\title{
Identificação e pertencimento: a importância de construir laços que aproximam pessoas com doenças raras
}

\author{
Aline Maran Brotto ${ }^{1}$ \\ Caroline Filla Rosaneli ${ }^{2}$ \\ Rui Fernando Piloto ${ }^{3}$
}

\begin{abstract}
Resumo
O sentimento de pertencimento e identificação em um grupo é essencial para que as pessoas se ajudem, bem como construam laços de afeto e confiança, que podem fortalecer-se com as dificuldades e os conflitos encontrados cotidianamente. O objetivo deste artigo é refletir sobre a importância de grupos de apoio e redes que acolhem e acompanham as pessoas com doenças raras. Para isso, realizou-se uma revisão narrativa, reflexiva e interpretativa de textos que abordam a relação de grupos de apoio e qualidade de vida. É possível constatar que o cuidado é um elo que une muitas famílias e histórias de vidas distintas, mas que, na sua diversidade, o afeto e a união são ingredientes importantes para a compreensão e a superação dos conflitos.
\end{abstract}

Palavras-chave: Grupo de apoio. Psicologia. Identificação. Doença rara.

\begin{abstract}
The feeling of belonging and identification in a group is essential for people to help each other, as well as to build bonds of affection and trust, which can be strengthened with the difficulties and conflicts encountered daily. The purpose of this article is to reflect on the importance of support groups and networks that welcome and accompany people with rare diseases. For this, a narrative, reflective and interpretive review of texts was carried out that deal with the relationship between support groups and quality of life. It is possible to verify that care is a link that unites many families and different life histories, but that, in their diversity, affection and unity are important ingredients for understanding and overcoming conflicts.
\end{abstract}

Keywords: Support group. Psychology. Identification. Rare disease.

É importante falar sobre pertencimento, pois existe uma discrepância em receber um diagnóstico de uma doença que "muitas" outras pessoas possuem e que o tratamento ou mesmo o nome da doença é conhecido e brevemente compreendido, de outras pessoas que recebem um diagnóstico de uma doença que, talvez, nunca ouviram falar, e que um número pequeno de pessoas

\footnotetext{
${ }^{1}$ Mestranda em Bioética com ênfase em doenças raras e saúde mental (PUC-PR), especialista em Neuropsicologia pelo UNYLEYA EDITORA E CURSOS S/A e Graduada em Psicologia (PUC-PR).

${ }^{2}$ Doutora em Ciências da Saúde (PUC-PR), Mestra em Alimentos e Nutrição (UNICAMP) e Graduada em Nutrição (UFSC).

${ }^{3}$ Doutor em Genética (UNICAMP), Mestre em Genética (UFPR) e Graduado em Medicina (UFPR).
}

Fed. Nac. das Apaes- Fenapaes $\mid$ Brasília/DF $\mid$ v.13 | nº | 1 P. 3 - 16 |jan./jun.2020|ISSN 2237-4329 


\section{Apøe Ciênciø Artigo}

apaeciencia.org.br/revista

no país ou no mundo também a possuem. Viver a experiência de ter passado ou estar passando por um diagnóstico de doença rara, muito provavelmente traz as incertezas do segundo grupo de pessoas mencionado, por não saber o que a doença é e faz ou não conhecer alguém que tenha passado por isso. Este texto, portanto, traz consigo uma reflexão sobre o sentimento de pertencimento e identificação de pessoas com doenças raras.

Em todo o mundo, existe em torno de 300 milhões de pessoas que vivem hoje com uma patologia considerada rara, ou seja, $4 \%$ da população mundial. Uma doença é considerada rara quando não afeta mais de 5 em um grupo de 10.000 pessoas. Sabe-se também que o número de doenças raras que permeiam por volta de 6 a 8 mil variações pode não ser fidedigna com a realidade, derivado do motivo de inúmeras doenças raras não serem rastreáveis nos sistemas de saúde ou não terem um diagnóstico preciso. Logo, percebe-se que é vasto o número de doenças raras, mas existem doenças que apenas uma ou duas pessoas no mundo possuem (ou pelo menos que tiveram diagnóstico). Existe uma porcentagem média de sobrevida de que 70\% das pessoas com doenças raras vivem até os cinco anos de idade, mas isso irá variar, dependendo dos tratamentos, medicamentos e até mesmo do próprio diagnóstico; $75 \%$ delas afetam crianças e $80 \%$ têm origem genética. As doenças raras geralmente são crônicas, progressivas, degenerativas e, muitas vezes, fatais (EURODIS, 2019; OMS, 2018).

É relevante apontar que quando uma pessoa está enferma, a família inteira, em algum grau, adoece. Portanto, se filho (a), esposo (a), pai, mãe ou outra pessoa próxima, dentro no núcleo familiar adoece, toda a família padece também, de maneiras diferentes. Portanto, encontrar alguém que passe pela mesma situação traz consigo um sentimento de empatia, que significa um processo de identificação em que o indivíduo se coloca no lugar do outro e, com base nas suas próprias suposições ou impressões, tenta compreender o comportamento do outro, gerando um sentimento de pertencimento - de acolhimento verdadeiro - que tem por significado a maneira de receber ou de ser recebido e/ou consideração. Esses sentimentos fazem com que a troca de experiência, relatos, dúvidas e superações sejam comemoradas e sentidas mediante um compartilhamento. A tendência de pessoas que passam por situações parecidas criarem um vínculo é grande e esse pode ser um canal de diálogos que aproxima mais pessoas que vivem de modo semelhante (SOARES; ARAÚJO; BELLATO, 2016).

Talvez um exemplo mais palpável é quando duas pessoas que nasceram ou moraram no mesmo lugar se encontram em um terceiro espaço, imaginemos dois brasileiros se encontrando por acaso em outro país. Existe uma grande probabilidade das pessoas perguntarem ou afirmarem algo 


\section{Apøe Ciênci@ Artigo}

apaeciencia.org.br/revista

sobre a cidade ou mesmo perguntarem onde estudou, qual o lugar que a pessoa ia para se divertir, dentre outras coisas. Todos os indivíduos passaram por algo parecido e se não fizeram perguntas ou afirmaram algo, no mínimo tiveram um sentimento de pertencimento ou mesmo nostalgia (PAISRIBEIRO, 2007).

Ter com quem contar é salutar para qualquer pessoa e ter alguém que vivencie algo parecido é ainda mais acolhedor. Cada qual possui a sua história, as suas vivências, em um ambiente diferente, com contextos distintos, mas as pequenas - grandes - coisas em comum são extremamente relevantes para o diálogo e a saúde mental, ou seja, não se sentir só.

De acordo com Bauman (2003), no livro "Comunidade: a busca por segurança no mundo atual", a construção da identidade é um processo que não acaba, passível de mudança, experimentação, sem ter um caráter definitivo, sendo construída, portanto, ao longo da vida.

É necessário cativar os sentimentos de pertencimento e identidade, de tal maneira que emerjam reflexões críticas sobre responsabilidade, cuidado, respeito, proteção, solidariedade, compromisso e honestidade individual e comunitária, que de alguma maneira toda a sociedade pode estar atenta. A noção do sentimento de pertencimento é intrínseca, já que a todo instante as pessoas aprendem o que é comum - traz insegurança - a aquilo que é diferente - e pode trazer estranheza inicialmente. Ao longo da vida pareamos sentimentos a situações, objetos ou pessoas. O sentimento derivado disso, junto ao pertencimento, seriam valores e atitudes (MORICONI, 2014).

O sentimento de pertencimento, acolhimento, identificação e empatia pode estar relacionado diretamente com o sentimento de comunidade, como: fazer parte de um grupo, influência, integração e satisfação das necessidades e partilha de ligações emocionais em relação a um grupo ao qual podemos chamar de comunidade, ou seja, pessoas que se conhecem ou se encontram por algum motivo que os une. O resultante do cuidado em grupo gera sentimentos subjetivos, mas que, em grande parte, possuem relação com a qualidade e a satisfação de vida, logo, mostram que estar em grupo ou em comunidade melhora o bem-estar de uma forma geral (ELVAS; MONIZ, 2010).

A Psicologia sócio-histórica pontua a necessidade de compreender os fenômenos históricos e sociais que indivíduos que passam por situações semelhantes trazem consigo, bem como a constituição de grupos de pessoas que se encontram ou se reúnem de alguma maneira, por terem objetivos em comum ou se identificam por algum motivo, como por exemplo, uma doença rara. Para Sawaia (2010), a perspectiva da Psicologia sócio- histórica busca despertar para o sentimento de culpa que os indivíduos podem carregar, como, por exemplo: não se sentirem confortáveis em um espaço

| Fed. Nac. das Apaes- Fenapaes $\mid$ Brasília/DF $\mid$ v.13 | nº | P. 3-16 | jan./jun.2020| ISSN 2237-4329 
que não existem pessoas que saibam acolher indivíduos com doenças raras (e/ou deficiências), por não estar adaptado para tal.

No Brasil, são 13 milhões de pessoas com doenças raras, mas não se sabe quantas dessas participam de grupos de apoio ou de mobilizações sobre enfermidades raras; o que se sabe, é que é relativamente difícil encontrá-las. É possível observar a construção de políticas que são reconhecidas como inclusivas, mas na verdade reforçam a desigualdade social, uma vez que não acolhem e adaptam espaços para influenciar e cativar a importante participação de todos em locais públicos que devem ser capazes de receber todas as pessoas (TAVARES, 2014; SAWAIA, 2010).

Diversos fatores, tais como responsabilidades, questões sociodemográficas e outros fatores geram estresse e claudicação, frente ao cuidado da pessoa com doença. A claudicação pode ser definida como:

Uma circunstância da perda de capacidade dos membros de uma família diante da resolução dos problemas do paciente devido à sobrecarga de responsabilidades que os mesmos exercem, diante da condição na qual o doente passa a depender exclusivamente dos cuidados de seus familiares e em um dado momento, decorrente da exaustão de tarefas que acabam despertando no cuidador sentimentos de medo e estresse e, a família não consegue encontrar recursos para responder às necessidades do seu ente querido. Vale ressaltar que esse processo pode se estender até após a morte do paciente, quando a equipe necessita trabalhar o processo de luto dessa família (MEIRELES et al., 2012, p. 6).

É fundamental pontuar como o SUS acolhe esses familiares e pessoas com doenças raras e/ou deficiência. Segundo o Art. $4^{\circ}$, a Política Nacional de Atenção Integral às Pessoas com Doenças Raras tem como objetivo o seguinte:

Reduzir a mortalidade, contribuir para a redução da morbimortalidade e das manifestações secundárias e a melhoria da qualidade de vida das pessoas, por meio de ações de promoção, prevenção, deteç̧ão precoce, tratamento oportuno redução de incapacidade e cuidados paliativos (BRASIL, 2014, p. 2).

Automaticamente, ao cuidar da pessoa com doença rara e/ou deficiência, de alguma maneira, está sendo cuidada essa família como um todo. O aspecto de cuidado da família é salutar para haver qualidade de vida (BRASIL, 2014).

No que tange ao Art. 13, que consiste em pontuar a linha de cuidado da atenção aos usuários com demanda para a realização das ações na Política Nacional de Atenção Integral às Pessoas com Doenças Raras é estruturada pela Atenção Básica e Atenção Especializada, em conformidade com a Redes de Atenção à Saúde - RAS e seguindo as Diretrizes para Atenção Integral às Pessoas com Doenças Raras no SUS, observa-se que existe um cuidado em "avaliar a vulnerabilidade e a capacidade de autocuidado das pessoas com doenças raras e realizar atividades educativas, conforme

| Fed. Nac. das Apaes- Fenapaes $\mid$ Brasília/DF $\mid$ v.13 | nº | P. 3 - $16 \quad$ jan./jun.2020| ISSN 2237-4329 


\section{Apøe Ciênci@ Artigo}

apaeciencia.org.br/revista

necessidade identificada, ampliando a autonomia dos usuários e seus familiares", melhorando, assim, o bem-estar de ambos.

Essa melhora de condição de vida, ou vida digna, pode ser também observada pela busca da promoção e acessibilidade que as RAS (Redes de Atenção à Saúde) e Comissão Nacional de Incorporação de Tecnologias no SUS (CONITEC) e Protocolos Clínicos e Diretrizes Terapêuticas (PCDT) podem proporcionar às famílias e pessoas com doenças raras. Dessa forma, é minimizada a vulnerabilidade presente quase que cotidianamente na vida de muitas pessoas (BRASIL, 2014).

Mediante questões relevantes da trajetória de vida da família e pessoa com doença rara, como o acompanhamento que o SUS fornece, é relevante perceber especificamente algumas vulnerabilidades durante esses itinerários terapêuticos. Seriam essas, portanto, as vulnerabilidades de acesso a saúde, social e moral.

A primeira dessas vulnerabilidades mencionadas seria a de acesso à saúde, que está relacionada à falta de informação ou informações desconexas dos profissionais da saúde. Infelizmente, ainda é comum que familiares possuam mais informação sobre o caso do paciente ou mesmo conhecimento da doença ou deficiência, do que a equipe de saúde. A falta de informação gera angústias de quem depende dela, especialmente ao se tratar do campo da saúde e de questão tão particulares e específicas. Encontrar profissionais que tenham conhecimento sobre uma doença, transmite o um sentimento de conforto e tranquilidade muito próximos ao de identificação e pertencimento, pois a família e os profissionais de saúde "falam a mesma língua" (FELIPE, 2017; PETER, 2015).

Outra vulnerabilidade que pode ser observada nesse contexto é a social, desde as preocupações que o tratamento traz consigo, até tratamentos medicamentosos (em grande parte de alto custo) e cuidados específicos necessários no manejo de cada doença. A vulnerabilidade social, muitas vezes, impede, pelas barreiras de acesso à informação e ao diálogo, que outras pessoas transmitam informações e experiências sobre a trajetória terapêutica vivenciada (FELIPE, 2017; MONTEIRO, 2011).

A última vulnerabilidade destacada neste texto é a moral, que envolve questões que englobam indivíduos e grupos que em sua condição de raridade são de alguma forma esquecidos, estigmatizados e discriminados, logo, moralmente estão mais suscetíveis ao sofrimento. Tal sofrimento talvez não diminua por si só, mesmo com a identificação e o acolhimento que uma pessoa possa receber, mas a maneira que o indivíduo lidará com esse sofrimento é que será alterado, pois a interpretação que

| Fed. Nac. das Apaes- Fenapaes $\mid$ Brasília/DF $\mid$ v.13 | nº | P. 3 - $16 \quad$ |jan./jun.2020|ISSN 2237-4329 
damos a um sentimento é que modificará a maneira a qual escolhemos carregar ou não esse sentimento inicialmente ruim (SANCHES; MANNES; CUNHA, 2016; FELIPE, 2017).

As vulnerabilidades podem ser observadas no que o Simpósio Internacional sobre a Bioética e os Direitos da Criança (Associação Mundial dos Amigos das Crianças) e UNESCO (2000) pontuaram, em que afirmaram que a sociedade deve promover, pesquisas relativas às doenças raras e ao desenvolvimento de terapias eficazes, o que aborda a relevante participação da família.

\begin{abstract}
Reconhecer que a questão da infância é uma realidade complexa em evolução e que merece agora consideração especial. As crianças são seres frágeis, mas sua autonomia não deve ser mal compreendida. Portanto, seus direitos - em especial os direitos à sobrevivência, ao desenvolvimento e à participação - e a proteção de que necessitam encontram-se refletidos efetivamente em numerosos textos nacionais e internacionais que visam à proteção dos direitos humanos, aos quais são acrescentados dispositivos específicos relativos às crianças, especialmente na Convenção Internacional sobre os Direitos da Criança (AMADE; UNESCO, 2000, p. 1)
\end{abstract}

De acordo com o Manual Diagnóstico e Estatístico de Transtornos Mentais, na quinta edição, DSM-5 (American Psychiatric Association - APA, 2013) aponta que certas doenças raras, como por exemplo a Doença de Príon e a Doença de Huntington podem ser de difícil e longo diagnóstico, pois podem ser confundidas com doenças psiquiátricas, bem como, a Eurordis (2019) pontua que doenças raras como, Cornélia de Lange, Fenilcetonuria e Adrenoleucodistrofia também podem demorar para haver diagnóstico, por haver poucos casos com tais doenças e, portanto, o diagnóstico é mais complexo. Contudo, não existe um consenso sobre a melhor definição sobre a problemática do que é um diagnóstico difícil, mas o especial fato do problema ser multifatorial traz grandes complexidades para o diagnóstico.

Existem os fatores do paciente que abordam listas imensas de queixas ou com imensos volumes de exames. $\mathrm{O}$ excesso de informação acaba sendo um entrave ao raciocínio do médico, que se vê paralisado diante de tantos sintomas e resultados de exames. Talvez por esse motivo, aconteçam atrasos ou erros diagnósticos e em contrapartida, as limitações do sistema de saúde são um grande entrave para a avaliação e exames específicos.

A bioética intervém no discurso dos conflitos éticos, quando pontuada questões de vulnerabilidade, vulneração e vulnerados, sendo a bioética da proteção que media nas relações sociais. São necessárias técnicas e manejos adequados e específicos para que o tratamento seja realizado, de acordo com a necessidade da pessoa, com metas e objetivos para a serem alcançados (BROPHY, 2013; SCHRAMM, 2008).

| Fed. Nac. das Apaes- Fenapaes $\mid$ Brasília/DF $\mid$ v.13 | nº | P. 3 - $16 \quad$ jan./jun.2020| ISSN 2237-4329 
Alguns paradigmas da bioética na Comissão Nacional de Bioética da Itália (2013) demonstram que:

Para promover o fortalecimento da pesquisa de doenças, no ciclo de vida e os tratamentos terapêuticos apropriados também na idade adulta com uma pesquisa que preenche a lacuna que existe hoje entre o avanço do conhecimento biológico é que a pesquisa de laboratório de neurociência e no campo, o que é necessário para padronizar as regras de comunicação e refutação de acordo com os últimos critérios de objetividade; garantir o direito à escolha consciente do cuidado, através do pedido de consentimento informado aos pais ou ao sujeito, no caso de um adulto capaz de compreender e querer, antes de qualquer tratamento - o pressuposto de que cada tratamento pode, se não houver possibilidade de confiantemente ser eficaz, assim, um desperdício nocivo de tempo e energia - demanda que deve incluir uma vasta informação sobre os diferentes tratamentos disponíveis e relativos cenários de eficiência; garantir o direito aos cuidados de saúde, através da verificação e manutenção do diagnóstico, e garantir a continuidade das intervenções educativas - adequadas à patologia e idade ao longo de toda a trajetória de vida; recorrer a intervenções farmacológicas apenas no interesse da pessoa; garantir o direito de desenvolver habilidades, não apenas fornecer ao adolescente e jovem adulto uma capacidade executiva específica, mas também cuidando de uma preparação cultural adequada de acordo com as habilidades demonstradas pelo sujeito; não dispersar os resultados do possível aperfeiçoamento das habilidades executivas, obtidas com algumas das técnicas de capacitação, isso pode ser alcançado aumentando as possibilidades de colocação no emprego por meio de políticas econômicas e sociais voltadas para pessoas com deficiências, organizando serviços ad hoc de tutoria e reagindo a todas as formas de ‘estigmatização' (CNB, 2013, p. 115).

É importante identificar as demandas e as necessidades da pessoa com doença rara e sua família, para então organizar as prioridades. Realinhar e redefinir as hipóteses e estratégias de intervenção que foram previamente estipuladas, talvez seja o próximo passo a ser tomado, mas além da identificação de aspectos culturais, étnicos, religiosos, deve-se observar as questões econômicas, políticas, ambientais, o grau de desigualdade social, e maiores vulnerabilidades no lugar em que se vive (SILVA; SUDIGURSK, 2008).

A ONU (Organização das Nações Unidas) em 2006 pontou que:

A universalidade, a indivisibilidade, a interdependência e a inter-relação de todos os direitos humanos e liberdades fundamentais, bem como a necessidade de que todas as pessoas com deficiência tenham a garantia de poder desfrutá-los plenamente, sem discriminação (ONU, 2006, p. 2).

Esse apontamento, seja para a pessoa com deficiência e/ou doença rara, ressalta questões elementares que o SUS traz consigo, como por exemplo a equidade, igualdade e universalidade, que buscam garantir que a tecnologia assistiva em "produtos, equipamentos, recursos, metodologias, estratégias, práticas e serviços promovam a funcionalidade" à vida da pessoa com deficiência e assim, melhore e aprimore a sua autonomia, qualidade de vida e inclusão social, que engloba o direito à cultura, ao esporte, ao turismo e ao lazer. Portanto, podem existir barreiras, que podem ser superadas e sentidas por um grande grupo de pessoas (BRASIL, 2015).

| Fed. Nac. das Apaes- Fenapaes $\mid$ Brasília/DF $\mid$ v.13 | nº | P. 3-16 | jan./jun.2020| ISSN 2237-4329 


\section{Apøe Ciênci@ Artigo}

O olhar bioético mediante aspectos bio-psico-sociais-espirituais contribui para a construção de políticas públicas igualitárias, acessíveis e de qualidade, o que se relaciona direta e indiretamente para a construção do sentimento de pertencimento da pessoa com doença rara e sua família, pois, assim, pode-se proporcionar melhores condições de vida a pessoas com doenças raras, suas famílias e a população no geral (AMARAL et al., 2016).

A desconstrução de ideias e ideais mediante a maneira que os indivíduos devem agir em sociedade, ainda não está preparada para abraçar de forma adequada todas as pessoas com deficiência e/ou com doença rara e os seus familiares. A criança, o adolescente, o adulto, o idoso e a sua família demandam, nesse momento, uma constante busca de melhor saúde e não evolução ou agravamento da doença rara que pode ter alguma condição de deficiência (KURCGANT et al., 2006).

Todos os direitos da família e da sociedade que vivem com pessoas com doenças raras devem estar disponibilizados na atual conjuntura em que vivemos. Os direitos não são acessíveis muitas vezes, como, por exemplo, no caso dos planos de saúde, os inúmeros exames, bem como os medicamentos de alto custo. O Comitato Nazionalle per la Bioética - CNB (2013) aponta que o começo é a criação e luta por políticas públicas que acolham a vulnerabilidade nas doenças raras.

Quando discutido sobre identificação e a trajetória terapêutica, neste texto, pode ser elencado inúmeros pontos que, no momento, trazem a reflexão da importância do cuidado, que pode ser paliativo. O cuidado paliativo, ao longo dos anos foi ampliado para as áreas de neonatologia e pediatria, prematuros extremos, malformação congênita grave, evolução das doenças crônicodegenerativas, dentre outras doenças raras. $\mathrm{O}$ conceito de cuidado paliativo obedece à definição de assistência efetiva e integral, direcionado a crianças, adolescentes, adultos e idosos fora de possibilidades terapêuticas de cura e aos seus familiares. A temática dos cuidados paliativos se demonstra em crescimento na pediatria, já que doenças crônicas e/ou genéticas em algumas situações podem levar à morte e afetam as crianças e os adolescentes. Logo, o processo de morte e morrer também deve ser levado em consideração (SILVA; SUDIGURSK, 2008).

Alguns pilares importantes dos cuidados paliativos podem acontecer nas etapas iniciais da doença, em combinação com terapias específicas ao diagnóstico e prognóstico. A qualidade de vida é um desses pontos importantes, pois, em qualquer momento ou estágio de uma doença, é salutar que a atenção esteja voltada para a busca pela qualidade de vida no momento de finitude, como o alívio e o controle dos sintomas, suporte espiritual, psicossocial e esses pontos se voltam para o paciente e a família. A abordagem humanista e a valorização da vida seriam outro ponto relevante e que tem 


\section{Apøe Ciênci@ Artigo}

apaeciencia.org.br/revista

caráter estritamente humanista, como compaixão, humildade, honestidade e valorização da vida, com a adoção de medidas e condutas que respeitem e compreendam o indivíduo como um ser bio-psicosocial-espiritual, com valores, metas e objetivos individuais e familiares.

Um outro ponto relevante nesse contexto de cuidados paliativos nas doenças raras é o controle e o alívio da dor e dos demais sintomas, que se foca na concepção de minimizar o sofrimento e sintomas. A dor pode ser descrita como desconfortos de caráter físico, psíquico, social e espiritual, tais como: "lesões cutâneas, odores desagradáveis, anorexia, caquexia, insônia, fadiga, luto antecipado, dificuldades econômicas, depressão, entre outros" (SILVA; SUDIGURSK, 2008).

A dor mal controlada causa impacto além do âmbito físico, tanto para a pessoa com doença rara, quanto para a família e até mesmo profissionais da saúde. Quando olhamos para essa esfera, designa-se o termo "dor total", uma vez que a dor envolve fatores físicos, emocionais, sociais e espirituais, que influenciam na vivência e na expressão da queixa de dor (SILVA; SUDIGURSK, 2008).

A espiritualidade é considerada uma ferramenta relevante para o apoio no luto, que se inicia com a morte da saúde, que dá lugar à presença da doença. Indivíduo e família enfrentam questões de natureza existencial, nas quais valores e crenças influenciam a tomada de decisão e realização de planos em curto, médio ou longo prazo. A necessidade de aliviar o sofrimento espiritual, não somente durante o curso da enfermidade, mas também no momento do luto, pelo apoio da equipe multidisciplinar em todos os aspectos é um fator a ser considerado (SILVA; SUDIGURSK, 2008).

A experiência das pessoas e famílias abordadas nos estudos realizados por Souza et al. (2019) demonstra o impacto de receber o diagnóstico de um adoecimento raro, a necessidade de cuidado que os adoecidos demandam, o aprendizagem de lidar com o cenário que se instaura, que muitas vezes é permeado por estigmas e preconceitos de diversas ordens, os sentimentos e as emoções envolvidos em todo processo de viver e cuidar, a espiritualidade como instrumento para lidar com a situação. $\mathrm{O}$ SUS e a ONU buscam minimizar o sofrimento que pode acontecer, pela falta de acesso e recursos para a qualidade de vida (ONU, 2006; BRASIL, 2015).

Logo, questões como dignidade no processo de morrer, autonomia para decidir sobre a vida, não abreviação da vida ou prolongamento artificial, promover a beneficência, a não maleficência e a justiça, como já pontuados também são pontos salutares da bioética, já que promover a autonomia é uma maneira de legitimar o sentimento de autossuficiência, do "eu entendo o que é melhor para mim". Portanto, dá-se voz quando se trabalha a bioética e nesse leque que essa ciência abrange, olhamos 


\section{Apøe Ciênci@ Artigo}

apaeciencia.org.br/revista

para a vertente dos cuidados paliativos, que não estão voltados apenas para o fim de vida, mas para o suprassumo do bem-estar em qualquer momento da vida (WIEGAND; ROSANELI, 2019; SILVA; SUDIGURSK, 2008).

No que tange aos cuidados paliativos, entendidos como cuidados voltados para a pessoas fora da viabilidade da cura, o cuidado se torna imprescindível. Portanto, o foco é o cuidado que tem prioridade sobre a cura e, assim, aproxima-se o contexto de sentimento de pertencimento e identificação, pois, de alguma maneira, eles estão presentes sem que indivíduo com doença rara e família "percebam", mas, muitas vezes, esses elementos primordiais dos cuidados paliativos estão de alguma maneira sendo levados em consideração.

O cuidado é a pedra fundamental do respeito e da valorização da dignidade humana, sobre o qual tudo o mais deve ser construído. Esse cuidado pode ser buscado junto aos órgãos sociais, bem como, condutas das Redes de Atenção à Saúde, que têm o dever de auxiliar, possibilitando, assim, uma melhor rede de apoio e sentimento de equidade. Em outras palavras, as famílias se sentem respeitadas e ouvidas na sua diversidade, garantindo, portanto, o atendimento e o cuidado necessário, assim, indiretamente se é abraçado e se tem o sentimento de valorização da sua fala e história (SILVA; SUDIGURSK, 2008; BRASIL, 2014; BRASIL, 2015).

Portanto, o cuidado com esses cuidadores é associado diretamente com o que uma pessoa com alguma doença rara possui - no caso -, pois dos menores aos maiores afazeres que o cuidador familiar terá para fazer, a pessoa com doença rara muitas vezes perceberá e sentirá que está sendo “descuidada" ou não cuidada o suficiente. É importante considerar que o apoio diário prestado pelos cuidadores familiares, passa, muitas vezes, despercebido ou sem reconhecimento social e inúmeras vezes até mesmo familiar. Os grupos e espaços de diálogo com pessoas que vivenciam as diversidades cotidianas nas doenças raras, pode restaurar e aliviar o "peso" que o cuidado demanda. Esses grupos ou espaços podem também fazer parte da Estratégia Saúde da Família (ESF) e do Programa de Agentes Comunitários de Saúde (PACS) que, de alguma maneira, podem também acolher a família na sua situação (MEIRELES et al., 2012; BRASIL, 2015; OMS 2018).

Collière (1999) afirmou que o ato de cuidar de um familiar pode produzir sobrecarga em diversas intensidades, podendo portanto, acabar comprometendo a saúde, a vida social, a relação com os outros membros da família, o lazer, a disponibilidade financeira, a rotina doméstica, o desempenho profissional e outros aspectos da vida pessoal e familiar. Logo, os cuidadores familiares realizam um 


\section{Apøe Ciênciø Artigo}

apaeciencia.org.br/revista

vasto número de tarefas, que podem ir desde "vigiar", ou seja, estar atento ao outro, ao acompanhar a medicação e outras consultas, sem horário limite para o trabalho ou tempo certo para descanso.

Então, os cuidadores familiares, muitas vezes, não enxergam tempo para o autocuidado, descanso e conforto, vendo nos grupos de pessoas que passam por situações parecidas um acolhimento que se transforma em união e amizade. A OMS (2018) aponta que mesmo não enxergando ter um tempo para cuidar de si, são elementares as tecnologias assistivas, que podem auxiliar muito nesse momento, pois se a pessoa com doença rara e/ou deficiência consegue cuidar de si, de algum maneira, como, por exemplo, tomar banho sozinho, arrumar a cama ou a mesa, dentre outros fatores, o cuidador familiar pode utilizar desse tempo para cuidar de si. Esse mesmo exemplo ilustra claramente a autonomia da pessoa com a doença rara e/ou deficiência.

O que foi exposto neste texto evidencia por si só não apenas um contexto psicológico e as relações de vulnerabilidade que a trajetória terapêutica traz consigo. Demonstra-se, também, a bioética, diante disso, unindo tais questões e acolhendo conflitos, contextos da saúde pública e exclusão social. Busca-se, portanto, estimular o senso moral individual e coletivo de cada um que possui amor e respeito pela vida e pela saúde de si mesmo e do outro. Mesmo com o contexto de apoio que as leis e o SUS respaldam, a família e as pessoa com doença rara e/ou deficiência necessitam, especialmente, de uma vida digna com funcionalidade, o que significa ter autonomia, independência, maior qualidade de vida, auxiliados pelas equipes de saúde, tecnologias assistivas e acolhimento na necessidade individual de cada família (GALINDO; GUTIÉRREZ, 2011; FELIPE, 2017; OMS, 2018).

O sentimento de saber como é viver, cuidar ou ter uma doença rara pode ser compartilhado, mas acontece mais rapidamente com pessoas que passam por situações semelhantes. Não ter outra pessoa com a mesma doença rara - no mesmo estado, país ou no mundo - e quando se conhece alguém que se encontra nessa "solidão", faz o sentimento de pertencimento estar presente. A identificação com outras pessoas fortalece os conflitos cotidianos e anima o compartilhamento de ideias e momentos, além de oferecer a possibilidade de criar amizades, o que, muitas vezes, um cuidador acaba deixando de lado. Há a clara necessidade de haver mais pesquisas e propostas de intervenções para a pessoa com doença rara, família e as próprias associações, sendo urgente ouvirmos e cuidarmos com dignidade de todos os envolvidos nesse contexto.

\section{REFERÊNCIAS}

|Fed. Nac. das Apaes- Fenapaes $\mid$ Brasília/DF |v.13 | nº | P. 3 - 16 |jan./jun.2020|ISSN 2237-4329| 


\section{Apøe Ciênciø Artigo}

apaeciencia.org.br/revista

AMARAL, D. L.; CARVALHO, F.; BARRETO A.; BEZERRA, A. C. Atenção bioética à vulnerabilidade dos autistas: a odontologia na estratégia da saúde da família. Rev. latinoam. Bioet., v. 16, n. 1, p. 220-233, 2016.

APA. AMERICAN PSYCHIATRIC ASSOCIATION. Manual Diagnóstico e Estatístico de Transtornos Mentais. 5. ed. Porto Alegre: Artmed, 2013.

BRASIL. Lei n. 13.146/2015, de 6 de julho de 2015. Institui o Código Civil. Diário da União: seção 1, Brasília, DF, p. 1-30, 7 jul. 2015. Disponível em: http://www.planalto.gov.br/ccivil_03/ato20152018/2015/lei/11 3146.htm\#: :text=LEI $\% 20$ N\%C2\%BA \%2013.146\%2C\%20DE\%206\%20DE\%20JULHO $\% 20$ DE $\% 2020 \quad 15 . \& \quad$ te

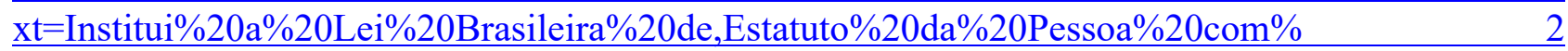
0Defici\%C3\%AAncia). Acesso em: 18 jun. 2020.

BRASIL. Decreto $n^{\circ}$ 6.949, de 25 de agosto de 2009. Institui o Código Civil. Diário Oficial da União: seção 1, Brasília, DF, p. 1-23, 26 ago. 2009. Disponível em: http://www.planalto.gov.br/ccivil_03/_ato2007-2010/2009/decreto/d6949.htm. Acesso em: 18 jun. 2020.

BRASIL. Ministério da Saúde. Gabinete do Ministro. Portaria $n^{\circ}$ 199, de 30 de janeiro de 2014. Institui a Política Nacional de Atenção Integral às Pessoas com Doenças Raras, aprova as Diretrizes para Atenção Integral às Pessoas com Doenças Raras no âmbito do Sistema Único de Saúde (SUS). Diário Oficial da União, Brasília, DF, 31 jan. 2014. p. 2. Disponível em: https://bvsms.saude.gov.br/b vs/saudelegis/gm/2014/ prt0199_30_01_2014.html\#: :text=PORTARIA\%20N\%C2\%BA\%20199\%2C\%20DE\%2030, instit ui $\% 20$ incentivos $\% 20$ financeiros $\% 20 \mathrm{de} \% 20$ custeio. Acesso em: 18 jun. 2020.

BROPHY, L. Crítica literária: ensino de ensaios discretos com crianças com autismo: um manual de auto-instrução. Ciência no Tratamento do Autismo, v. 10, n. 1, p. 14-15, 2013.

COLLIÈRE, M. F. Promover a vida. Lisboa: LIDEL - Tradições Técnicas Sindicato dos Enfermeiros Portugueses, 1999.

COMITATO NAZIONALLE PER LA BIOETICA. Conselho Nacional de Bioética. Presidenza del Consiglio dei Ministri disabilità mentale nell'età evolutiva: il caso dell'autismo. 2013. Disponível em: http://www.quotidianosanita.it/governo-e-parlamento/articolophp?articolo_ id=16464. Acesso em: 2 dez. 2018.

EURORDIS. European Organisation for Rare Deseases. Rare Diseases: Understanding this Public Health Priority. 2005. Disponível em: www.eurordis.org. Acesso em: 20 set. 2006.

ELVAS, S.; MONIZ, M. J. V. Sentimento de comunidade, qualidade e satisfação de vida. Análise Psicológica, v. 28, n. 3, p. 451-464, 2011.

|Fed. Nac. das Apaes- Fenapaes $\mid$ Brasília/DF $\mid$ v.13| nº | P. 3 - 16 | jan./jun.2020|ISSN 2237-4329 


\section{Apøe Ciênciø Artigo}

apaeciencia.org.br/revista

FELIPE, R. N. R. Vulnerabilidades perante os itinerários terapêuticos em doenças raras. 2017, 47 f. Dissertação. Programa de Pós-graduação em Bioética Pontifícia Universidade Católica do Paraná. Curitiba.

GALINDO, G. C.; GUTIÉRREZ, S. Y. Reflexiones bioéticas em torno alas enfermidades raras y huérfanas com impacto em el sistema bucodentario. Rev. latinoam. Bioet., v. 11, n. 1, p. 22-31, 2011.

KURCGANT, P.; TRONCHIN, D. M. R.; A construção de indicadores de qualidade para a avaliação de recursos humanos nos serviços de enfermagem: pressupostos teóricos. Acta Paul Enferm, v. 19, n. 1, p. 88-91, 2006.

LINDBLAD, T. L. Canto clínico: Como você aumenta a inteligibilidade de fala (habilidades de articulação) ou a variabilidade nos sons produzidos por crianças com transtornos do espectro do autismo? Ciência no Tratamento do Autismo, v. 9, n. 3, p. 3-6, 2012.

MEIRELES, N.; PEREIRA, A.; FERREIRA, A.; FERREIRA, S.; VIEIRA. E. O Papel parental e a Claudicação familiar: qual a importância do enfermeiro de Família? In: CARVALHO, J. C.; et al. Transferibilidade do conhecimento em enfermagem de família. Porto: ESEP, 2012.

MONTEIRO, S. R. R. P. O marco conceitual da vulnerabilidade social. Sociedade em Debate, v. 17, n. 2, p. 29-40, 2011.

MORICONI, L. V. Pertencimento e identidade. 2014. f. Trabalho de Conclusão do Curso (Licenciatura Plena em Pedagogia), Faculdade de Educação da Universidade de Campinas, Campinas, 2014.

ORGANIZAÇÃO MUNDIAL DA SAÚDE (OMS). Determinantes Sociais e Riscos para a Saúde, Doencas Crônicas Não Transmissíveis e Saúde Mental. 2018. Disponível em: https://www.paho.org/bra/index.php?option=com_conten t\&vi ew=article\&id=57 74:0 ms-lan cainiciativa-de-controle-do-uso-nocivo-de-alcool-para-prevenir-e-reduzir-mor tes- e-in capacidades\&Itemid=839. Acesso em: 18 jun. 2020.

ONU. Convenção da ONU sobre Direitos das Pessoas com Deficiência. 2006. Disponível em: https://www.fundacaodorina.org.br/a-fundacao/deficiencia-visual/co nvencao- da-onu -sobredireitos-das-pessoas-com-deficiencia/ Acesso em: 18 jun. 2020

PAIS-RIBEIRO, J. L. Introdução à Psicologia da Saúde. 2. ed. Coimbra: Quarteto, 2007.

PETER, E. The ethics in qualitative health research: special considerations. Ciência \& Saúde Coletiva, v. 20, n. 9, p. 2625-2630, 2015.

SANCHES, M. A.; MANNES, M.; CUNHA, T. R. Vulnerabilidade moral: leitura das exclusões no contexto da bioética. Rev. Bioét., v. 26, n. 1, p. 39-46, 2018.

|Fed. Nac. das Apaes- Fenapaes $\mid$ Brasília/DF |v.13 | nº | P. 3 - 16 |jan./jun.2020|ISSN 2237-4329| 


\section{Apøe Ciênciø Artigo}

apaeciencia.org.br/revista

SAWAIA, B. B. (Org.). As Artimanhas da Exclusão: análise psicossocial e ética da desigualdade social. Petrópolis, RJ: Vozes, 2010.

SCHRAMM, F. R. Bioética da Proteção: ferramenta válida para enfrentar problemas morais na era da globalização. Revista Bioética, v. 16, n. 1, p. 11-23, 2008.

SILVA, E. P.; SUDIGURSK, D. Concepções sobre cuidados paliativos: revisão bibliográfica. Acta paul. enferm., v. 21, n. 3, p. 504-508, 2008.

SIMPÓSIO INTERNACIONAL SOBRE A BIOÉTICA E OS DIREITOS DAS CRIANÇAS MÔNACO. Declaração de Mônaco: Considerações sobre a Bioética e os Direitos da Criança organizado pela Associação Mundial dos Amigos das Crianças. AMADE /UNESCO, 2000.

SOARES, J. L.; ARAÚJO, L. F. S.; BELLATO, R. Cuidar na situação de adoecimento raro: vivência da família e sua busca por amparo dos serviços de saúde. Saúde soc. v. 25, n. 4, p. 1017-1030, 2016.

SOUZA, Í. P.; ANDROLAGE, J. S.; BELLATO, R.; BARSAGLINI, R. A. Doenças genéticas raras com abordagem qualitativa: revisão integrativa da literatura nacional e internacional. Ciênc. saúde coletiva, v. 24, n. 10, p. 3683-3700, 2019.

TAVARES, R. C. O sentimento de pertencimento social como um direito universal. Caderno de Pesquisa Interdisciplinar em Ciências Humanas, v. 15, n. 106, p. 179-201, 2014.

WIEGAND, S. C. B.; ROSANELI, C. F. O luto infantil nas doenças raras. Revista Ibero Bioética, v. 10, p. 1-11, 2019.

Fed. Nac. das Apaes- Fenapaes $\mid$ Brasília/DF $\mid$ v.13 $\mid n^{\circ} 1 \quad$ P. 3 - 16 |jan./jun.2020||ISSN 2237-4329| 